\title{
The Distinctive Features of a Picture of the World of the Students of Pharmaceutical Faculty
}

\author{
Ildar R. Abitov ${ }^{1}$ \\ ${ }^{1}$ Kazan (Volga region) Federal University, Kazan, Russia \\ Correspondence: Ildar R. Abitov, Kazan Federal University, Kremlyovskaya Street 18, Kazan, 420008, Russia. \\ E-mail: ildar-abitov@yandex.ru
}

Received: January 19, 2014

Accepted: February 22, 2015 Online Published: March 25, 2015

doi:10.5539/res.v7n5p47

URL: http://dx.doi.org/10.5539/res.v7n5p47

\begin{abstract}
The relevance of the studied problem is caused by the lack of the uniform model of a picture of the world of the professional and the insufficient number of the researches of a picture of the world of the pharmacists. The purpose of this article is the acquaintance of the psychologists working in the educational institutions and the pharmaceutical companies with the results of the research of a picture of the world of the students of the pharmaceutical faculty of medical school, which work in the specialty. The main result of this research is the empirical confirmation of the model of the picture of the world that includes the belief about the goodwill and justice of the world around, the one's own value and importance, the luck and ability to control the events of the life, about the future and about the efficiency of the professional activity. The materials of the article can be useful for the psychologists of the educational institutions in which there are pharmaceutical faculties, and also for the psychologists working in the pharmaceutical companies and pharmacy chains.
\end{abstract}

Keywords: beliefs, pharmacists, the picture of the world, model of the picture of the world

\section{Introduction}

The Great demands are made for druggists and pharmacists in society for a long time: they have to get the profound knowledge in the field of medicines, know how to cook preparations on the basis of the recipe of the doctor, have the profound knowledge in the field of chemistry and biology, medicine. In the modern Russian society the pharmacist carry out not only the direct functions but also the other functions, not peculiar for this profession. In particular, buyers in drugstores often consult the pharmacist concerning the preparation to get, describe the complaints to various indispositions, and also look for psychological support. The professional activity of the pharmacists in our country is connected with a large number of contacts with clients, with the emotional loadings, the high responsibility for the health of clients, with the frequent conflict situations (Cheverikina et al., 2014). In such conditions, the ideas of the pharmacists of themselves and their future, the view of the world around, of other people and of the pharmaceutical activity and its results are of particular importance for the efficiency of the professional activity and for the prevention of the professional deformation. In psychology, the category that most closely describes the ideas about themselves, about the others and about the world, is the categories of "worldview" and "the image of the world". Such researchers and practicians as Bayanova (2013), Beck (1987), Epstein (1990), Janoff-Bulman (1992), Padun and Kotelnikova (2012), Garanyan and Yudeeva (2008), Veraksa (2014) were engaged in studying of the formation and the functioning of the belief and the pictures of the world.

\section{Methodological Framework}

The cognitive-experimental personality theory by Epstein (1990), the three-layer model of the image of the world of professional by Serkin (2012), the "depressive triad" by Beck (1987) formed the methodological basis of this study.

For the determination of the features of the worldview of the druggists we conducted the research of 77 students of the fifth course of a correspondence department of pharmaceutical faculty of the Kazan state medical university. All selection is divided into two groups: 1) 47 students work as druggists in the various pharmacy chains (all the female respondents, age of examinees from 23 to 40 years); 2) 30 students that do not work in the specialty (all the female respondents, age of examinees from 23 to 34 years). The questionnaire "A scale of basic 
belief" was used (by Janoff-Bulman, adaptation by Padun \& Kotelnikova, 2011) for the diagnostics of the conception about itself, about other people and about the world around. "The scale of unhopeness by A. Beck" was used (Mikhaylov, Malikova, Shatrovoy, Mikhaylov \& Solomin, 2009) for the diagnostics of the conception about the future. "The Perfectionism questionnaire" (Garanyan \& Kholmogorova, 2008) was used for the diagnostics of the conception about the efficiency of the activity and its results. According to Padun and Kotelnikova (2012), the category "worldview" can be operationalized through the concept "the basic beliefs". These authors describe the cognitive - experimental theory of the identity by S. Epstein in the monograph "The Mental Trauma and The Picture of the World" (2012). According to S. Epstein's theory, people construct "the theory of reality" which includes the following blocks: the theory of "I", the theory of world around and the representation of the relations between "I" and the world around. According to this theory, people examine the reality by two ways: rational and experimental (by means of experience). The Information that acquired experimentally is fixed much more strongly, because of the expense of an emotional charge, with it closely connected with the experience. Thus, the constructs which are formed as a result of the process of generalization by the identity of emotionally significant experience at interaction with the world around, and are represented in the behavior of the person automatically, preceding on time to any rational processes, are called an "implicit concept". These conceptions formed the cornerstone of the theory of the reality.

S. Epstein allocated four types of basic requirements which satisfaction defines the behavior of the person: the requirement of maximizing of pleasure and minimization of pain, the requirement of the coherent and stable concept of the world around, the requirement of the object of attachment and the requirement of self-esteem. These requirements are satisfied by means of experimental and rational systems, but in their satisfaction the experimental system has special value.

According to the allocated requirements, the author emphasizes the basic concepts, which make a basis of the implicit theory of the reality: the belief about the goodwill of the world; the belief about the justice of the world; the belief that people can be trusted; the belief in one's own importance.

In a consequence, the method of the diagnostics of the basic belief was developed by Janoff-Bulman (1992), than it was modified by Padun and Kotelnikova (2011) who included the subscales: the belief about the goodwill of the world around, that reflects the belief of the individual of rather safe opportunity to trust the world around him; the belief about the justice of the world around - the belief that good and bad events are distributed between people on justice; the belief about control - the belief that the person can control the events happening to him; the belief about the value and the importance of the someone's own "I"- the belief of the individual that he is worthy love and respect; the belief about the good luck - the belief of the individual that in general he is the lucky person. The modified option of this method was used by us in this research for detection of features of the worldview of students of medical school.

Recently, under the leadership of Serkin (2012) a number of researches are carried out and the three-layer model of an image of the world of the professional is developed.

1) The Nuclear layer. Its contents, according to Serkin (2012), are submitted by the different motives and practically don't change in professionalizing process.

2) The semantic layer is defined by the "signatura rerum" (comprehension) of the world around, the attitude towards them.

3) The perceptual layer - the most mobile and changeable part of the image of the world of the professional. It includes all images of the actual perception connected with the professional activity.

Serkin (2012) notes that with the use of the complete three-layer model of an image of the world by the results of the various professional groups, the existence of the professional specificity of the semantic and perceptual layers of the image of the world was confirmed. In the medical psychology the great value is attached to the studying of the representations of an "I" image and of the image of the world around during the depressions.

Beck (1987) believes that the cognitive triad is the cornerstone of the depression: the negative basic belief about someone's owns "I", world around and negative view about the future. The interrelation between the basic conceptions and depression, and also other psychopathological symptoms was confirmed in the researches of the staff of laboratory of psychology of a post-traumatic stress of the Institute of psychology of the Russian Academy of Sciences. For the persons with the high level of depressiveness the negative idea of the world around and their own "I" is typical: the world is represented as spiteful, people - not worthy trust, and their own "I"- weak and worthless (Padun \& Kotelnikova, 2012). Also in medical psychology, the great attention is paid to the research of the interrelation between the perfectionistic conception of low efficiency of someone's own 
activity, its low results and such symptoms of boundary mental disorders as the increased anxiety and depressiveness (Garanyan \& Yudeeva, 2008).

Thus, among all the approaches to the study of the world picture, the approach that based on the allocation of the separate "blocks" which make up a complete picture of the world - beliefs, highlighting the most fundamental of them (basic) - the most preferred for us.

However, we find it possible to rework the world picture model offered by Padun and Kotelnikova (2012) and include into the model the conception about the future (optimistical or pessimistic) and the belief about the efficiency of the activity and its results. Then the model of the picture of the world takes the following form:

- Belief about goodwill of the world around;

- Belief about justice of the world around;

- Belief about control;

- Belief about luck;

- Belief about the value and the importance of someone's own "I";

- Belief about the future;

- Belief about the efficiency of the activity and its results.

\section{Results}

During the research the both studied groups showed the average values in all studied parameters, except the subscales "the Image of me" and "the good luck" of a questionnaire "A scale of basic belief". In both groups examinees estimate themselves as good, worthy love and respect, lucky and successful people that is typical for mentally healthy, stress-resistant people. To detect the differences between the study groups was used t-criterion by Student. One distinction between the studied groups is revealed. The examinees working in the specialty are less inclined to be guided by high standards of activity and by the most successful professionals $(p=0.004)$. This result can be connected with the fact that examinees of this group adapted for the professional activity and more rationally treat it, they don't idealize the professional activity while the examinees from the other group didn't work yet and they are only going to start being engaged in the future in the professional activity, or they work not on the specialty - therefore such students have the ideal, unrealistic ideas of a profession of the pharmacist.

For the identification of interrelations between the studied indicators the coefficient of linear correlation of Pearson was used. In both studied groups the indicator " the selection of information on failures and mistakes" is connected by the direct correlation with the indicator of the negative belief about the future (in the group of druggists: $\mathrm{r}=0.52 ; \mathrm{p} \leq 0.001$; in the group that not working in the specialty: $\mathrm{r}=0.55 ; \mathrm{p} \leq 0,01)$ and the reverse correlation with the indicator of belief about the value and the importance of their own "I" (in the group of druggists $\mathrm{r}=-0.42 ; \mathrm{p} \leq 0.01$; in the group not working in the specialty: $\mathrm{r}=-0.56 ; \mathrm{p} \leq 0.001$ ).

In the group of the students of pharmaceutical faculty working in the specialty the following correlation communications between the studied parameters are found. The indicator of the negative belief about the future has the direct correlation with the indicators "the perception of other people as delegating high requirements" $(\mathrm{r}=0.51 ; \mathrm{p} \leq 0.001)$ and the general indicator of the perfectionism $(\mathrm{r}=0.42 ; \mathrm{p} \leq 0.01)$.

In the group of the students working as pharmacists the feedback of the indicator of the negative belief about the future with the indicators of the belief about the value and the importance of their own " $\mathrm{I}$ " $(\mathrm{r}=-0.54 ; \mathrm{p} \leq 0.001)$, about the ability to control the events of the life $(\mathrm{r}=-0.59 ; \mathrm{p} \leq 0.001)$ and about the luck and luckiness $(\mathrm{r}=-0.59$; $\mathrm{p} \leq 0.001$ ) is found.

In the group of the students working in the specialty the feedback of the indicator «the perception of other people as delegating high requirements» with the indicators of belief about the goodwill of the world around $(\mathrm{r}=-0,40$; $\mathrm{p} \leq 0,01)$ and with the indicator of belief about the luck $(\mathrm{r}=-0.39 ; \mathrm{p} \leq 0.01)$ is found.

The direct link of the indicator "the overestimated claims and requirements" with the indicator of belief about control $(\mathrm{r}=0.41 ; \mathrm{p} \leq 0.01)$ is found.

\section{Discussions}

The examinees working in the specialty are less inclined to be guided by the high standards of the activity and by the most successful professionals. This result can be connected with the fact that examinees of this group adapted for the professional activity and more rationally treat it, they don't idealize the professional activity while the examinees from the other group didn't work yet and they are only going to start being engaged in the 
future in the professional activity, or they work not on the specialty - therefore such students have the ideal, unrealistic ideas of a profession of the pharmacist.

It is revealed that than more often the examinees of both groups are fixed on their mistakes and failures, then they negatively estimate the future and more negatively treat themselves. The data by Garanyan and Yudeeava confirm these interrelations, that such pattern of thinking as fixing on the failures and mistakes is characteristic for people with high depressiveness and uneasiness and can be connected with the components of "a depressive triad" of A. Beck: the negative assessment of itself and the future.

The received results specify that than more the students working as druggists are convinced that people around make great demands of them and than more they are convinced in low efficiency of their professional activity, then they are rather pessimistic concerning the future.

These interrelations indicate an inclusiveness of the conception about the future and the belief in efficiency of the professional activity in the united system and confirm the world picture model offered by us.

It is revealed that the more, the students working in the specialty are convinced of hopelessness of the future, the worse they view themselves, the luck and the ability to control the events of their life.

These interrelations coordinate with "a depressive triad" of Beck (1987), who assumed that in the depression the combination of a negative assessment of itself and the future is observed. These interrelations also indicate the inclusiveness of the belief about the future, about someone's own value and the importance, luckiness and ability to control the events of the life in the united picture of the world.

The more, examinees of this group are convinced that people around make great demands of them, the less friendly they perceived the world and the less they believe in the good luck.

These relationships confirm our assumption about the interrelations of beliefs about the effectiveness of their professional activity with the beliefs about the goodwill of the world and their own good luck, and also consistent with the data obtained by Garanyan, and Yudeeva (2008) about the importance of the perfectionist beliefs in the formation of the depression and anxiety.

Than examinees of this group are more inclined to make great demands of themselves and to be dissatisfied with the achieved results, the more they believe in their ability to control the events in the life.

This link reflects the feature of a picture of the world of the examinees of this group having the high claims, their aspiration to control the life in all its manifestations which can lead to the disappointments and failures of adaptation.

\section{Conclusion}

Thus, it is revealed that the examinees working in the specialty are less inclined to be guided by the high standards of activity and by the most successful professionals $(\mathrm{p}=0.004)$, than the examinees, the unemployed pharmacists.

It can be connected with their adaptation to the requirements of the professional activity and the lack of the idealization of the profession of druggist.

Also in the group of the students of pharmaceutical faculty working in the specialty the interrelations between the various "blocks" of the united picture of the world are found: the belief about the value and the importance of the own "I", about their own luck, the ability to control the events of the life, the goodwill and justice of the world around, about future and about efficiency of the activity and its results.

In the group of the students of pharmaceutical faculty working in the specialty 10 correlation links between the various conceptions are revealed. In the group of students, the unemployed in the specialty, only 2 links are revealed.

The obtained data speak about the high coherence of a picture of the world of the students working in the specialty and can serve the empirical evidence of the world picture model offered by us.

\section{Recommendations}

On the basis of the obtained data it is possible to formulate the following recommendations Due to the high coherency of a picture of the world in the group of the students of the pharmaceutical faculty working in the specialty, for the prevention of the development of a syndrome of the emotional burning out and the boundary mental disorders, it is necessary to include in the program of the training and professional development of the pharmacists the special course- "The training of the professional self-control" based on the studying of the bases of the cognitive and behavioral and rational-emotional approaches in the psychotherapy and directed on 
the formation of the skills of the identification of irrational belief (automatic thoughts) and their independent correction.

\section{Acknowledgments}

The work is performed according to the Russian Government Program of Competitive Growth of Kazan Federal University

\section{References}

Abitov, I. R., \& Kashapova, G. I. (2013). Features of a worldview and readiness of the students of the medical school for civil behavior, The identity of the professional in the modern world. In Institute of psychology of the Russian Academy of Sciences (pp. 465-475). M.

Bayanova, L., \& Khabutdinova, M. (2013). Norms and Values Characteristics of Students in a Foreign Cultural Environment. Middle-East Journal of Scientific Research, 16(11), 1527-1531.

Beck, A. T. (1987). Cognitive models of depression. Journal of Cognitive Psychotherapy: An International Quarterly, 1, 5-37.

Cheverikina, E. A., Rakhimgarayeva, R. M., Sadovaya, V. V., Zakirova, V. G., Starodubets, O. D., \& Klemes, V. S. (2014). Socio-psycological characteristics of college students who are prone to addictions. American Journal of Applied Sciences, 11(8), 1412. http://dx.doi.org/10.3844/ajassp.2014.1412.1417

Epstein, S. (1990) Cognitive experiental self-theory. In L. A. Pervin (Ed.), Handbook of personality: Theory and research (pp. 165-192). NY. Guilford.

Garanyan, N. G., \& Yudeeva, T. J. (2008). Diagnostics of perfectionism at frustration of an affective range (p. 19). A manual for doctors.

Janoff-Bulman, R. (1992). Shattered assumption: Toward a new psychology of trauma. NY. Free Press.

Mikhaylov, L. A., Malikova, T. V., Shatrovoy, O. V., Mikhaylov, A. L., \& Solomin, V. P. (2009). Psychological protection in emergency situations: Manual (p. 256). SPb. St. Petersburg.

Padun, M. A., \& Kotelnikova, A. V. (2011). Technique of research of basic belief of the personality. Psikhologicheskii Zhurnal, 29(4), 98-106.

Padun, M. A., \& Kotelnikova, A. V. (2012). Mental trauma and picture of the world: Theory, empiriya, practice. In Institute of psychology of the Russian Academy of Sciences (p. 206). M.

Serkin, V. P. (2012). Professional specifics of an image of the world and way of life. Psikhologicheskii Zhurnal, $33(4), 78-89$.

Veraksa, A., Gorovaya, A., Grushko, A., Bayanova, L., Melyausha, G., \& Dinara, G. (2014). Development and reliability of the Russian version of "The Sport Imagery Questionnaire". Anuario de Psicologia, 1(44), 45-54.

\section{Copyrights}

Copyright for this article is retained by the author(s), with first publication rights granted to the journal. This is an open-access article distributed under the terms and conditions of the Creative Commons Attribution license (http://creativecommons.org/licenses/by/3.0/). 